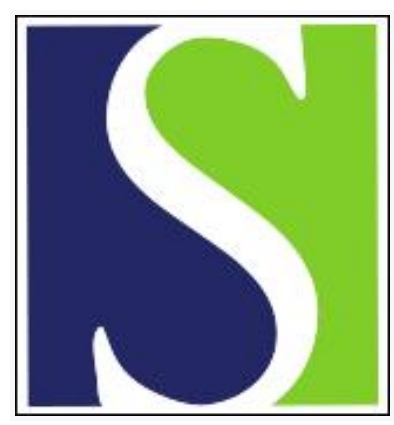

Scand J Work Environ Health 2009;35(6):475-478

https://doi.org/10.5271/sjweh.1359

Published online: 02 Oct 2009, Issue date: 00 Dec 2009

Occupational asthma caused by inhalation of surfactant composed of amines

by Villar-Gómez A, Muñoz X, Culebras M, Morell F, Cruz M-J

Affiliation: Servei de Pneumología (Pneumology Department), Hospital Vall d'Hebron, Barcelona; Facultat de Medicina, UAB, Barcelona, Spain.

Refers to the following text of the Journal: 2001;27(1):76-81

Key terms: amine; asthma; case report; cleaning product; inhalation; occupational asthma; specific inhalation challenge; surfactant; tensioactive agent

This article in PubMed: www.ncbi.nlm.nih.gov/pubmed/19806278

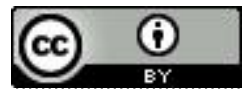




\title{
Occupational asthma caused by inhalation of surfactant composed of amines
}

\author{
by Ana Villar-Gómez, MD, ${ }^{1}$ Xavier Muñoz, MD, PhD,1, 2 Mario Culebras, MD, ${ }^{1}$ Ferran Morell, MD, PhD, ${ }^{1,2}$ \\ María-Jesus Cruz, PhD 1,2
}

\begin{abstract}
Villar-Gómez A, Muñoz X, Culebras M, Morell F, Cruz M-J. Occupational asthma caused by inhalation of surfactant composed of amines. Scand J Work Environ Health. 2009;35(6):475-478.
\end{abstract}

\begin{abstract}
Objective Occupational asthma (OA) is highly prevalent in industrialized countries and nearly 400 causal agents of this condition have been described to date. This study aims to describe the case of a patient who developed OA secondary to exposure to a surfactant agent comprised of alkylamine ethoxylate and a mixture of alkyleneoxy and ethylenediamine.
\end{abstract}

Methods We present the case of a male worker in the meat industry suffering from OA resulting from exposure to a surfactant agent used to clean an animal carcass before it is quartered. We performed various tests on the individual, including: a chest computed tomography; total serum immunoglobulin E (IgE) and specific $\operatorname{IgE}$ tests against common pneumoallergens; pulmonary function studies; a methacholine test; and a specific inhalation challenge to the surfactant agent.

Results The tests confirmed the diagnosis of OA.

Conclusions We discuss whether the amines present in the surfactant or the agent itself might be the cause of the condition. Because of the extensive use of surfactants in several types of industries, it is reasonable to think that their possible relationship with OA may have relevant health implications.

Key terms case report; cleaning product; specific inhalation challenge; tensioactive agent.

Recent studies have shown that cleaning professionals are at a particularly high risk of developing occupational asthma (OA) (1-2). In a study performed on 2656 subjects, Zock et al (3) found that substances such as ammoniac, bleach, and caustic soda can cause airway irritation. However, the authors also suggested that it cannot be excluded that cleaning products in general may be a cause of immunologic OA, since many contain sensitizing agents such as quaternary ammonium, ethylenediamine, and propylenediamine, or preservatives such as isothiazolinones. Moreover, it is known that many detergents used in domestic and professional cleaning activities contain proteolytic enzymes, which have been implicated in the genesis of OA (4). Tensioactive agents (ie, surfactants) are also present in many detergents. Since their development in the first half of the 20th century, these compounds have had numerous applications in metallurgy, the textile industry, agriculture, pharmaceutical products, and varnishes. Currently, however, they are found most extensively in cleaning products, as part of the composition of detergents (www.abacovital.com/ fichastecnicas/tensioactivos/tensioactivos.htm).

This study describes the case of a meat industry worker with $\mathrm{OA}$; the causative agent was found to be a non-ionic surfactant used to clean animal carcasses.

\section{Case description}

The case subject was a male 53-year-old, ex-smoker (60 pack-years) up to three years previously, with no other relevant family, personal or pathological history. He had been working in the pork industry for 22 years, where his main occupation was to clean and quarter the animal carcasses. Specifically, the patient worked on a production line where he received carcasses impregnated with a surfactant compound (alkylamine ethoxylate, and a mixture of alkyleneoxy and ethylenediamine) and

1 Servei de Pneumología (Pneumology Department), Hospital Vall d'Hebron, Barcelona; Facultat de Medicina, UAB, Barcelona, Spain.

2 CIBER Enfermedades Respiratorias (CIBERES), Instituto de Salud Carlos III, [national network], Spain.

Correspondence to: Dr Xavier Muñoz, Servei de Pneumologia, Hospital General Vall d'Hebron, Passeig Vall d'Hebron 119, 08035, Barcelona, Spain. [E-mail: xmunoz@vhebron.net] 
then quartered and washed them with distilled water. Over the past three years, the patient had experienced dyspnea on physical exertion, dry cough, asthenia, and occasional wheezing that had required emergency room visits on four occasions in the last year. The symptoms began in the middle of his workday, and improved on the weekends and during vacation periods. Auscultation disclosed decreased vesicular breathing sounds, and prolonged and sibilant exhalations. Laboratory analyses showed $8.3 \times 10$ E9/1 leukocytes, with $67 \%$ neutrophiles, 19\% lymphocytes, $9.4 \%$ monocytes, and $4 \%$ eosinophils. Total immunoglobulin E (IgE) concentration was $220 \mathrm{IU} / 1$, and specific IgE to common pneumoallergens was negative. Alpha-1 antitrypsin level was $123 \mathrm{mg} / \mathrm{dl}$ and the serum immunoglobulin study was normal. Chest computed tomography demonstrated bronchiolar involvement, with slight air trapping on expiratory scans and signs of emphysema. Pulmonary function testing revealed a severe obstructive ventilatory pattern with forced vital capacity (FVC) of 1.38 $1(30.2 \%)$, forced expiratory volume in one second $\left(\mathrm{FEV}_{1}\right)$ of 1.001 (29.1\%), $\mathrm{FEV}_{1}$ percentage $\left(\mathrm{FEV}_{1} \%\right)$ of $72.45 \%$, residual volume (RV) of 4.461 (208\%) and total lung capacity (TLC) of 6.341 (100\%). The lung transfer factor for carbon monoxide $\left(\mathrm{TL}_{\mathrm{CO}}\right)$ was normal $\left(\mathrm{TL}_{\mathrm{CO}} 80 \%\right.$ and $\mathrm{TL}_{\mathrm{CO}}$ /aveolar volume $97 \%$ of the theoretical value). The bronchodilation test was positive and showed an $\mathrm{FEV}_{1}$ increase of $76 \%$. After stopping work and initiating bronchodilator treatment, the patient's new pulmonary function testing showed FVC 3.641 (80\%), $\mathrm{FEV}_{1} 2.48 \mathrm{l}(73 \%)$ and $\mathrm{FEV}_{1} \%$ 68\%. The methacholine test was positive, with the provocative concentration producing a $20 \%$ decline $\left(\mathrm{PC}_{20}\right)$ of $1.3 \mathrm{mg} / \mathrm{ml}$.

With an asthma diagnosis that we suspected might be occupationally-based, we performed a specific inhalation challenge (SIC) with the surfactant agent that was used to coat the animal carcasses. The SIC was performed in a hospital setting with the patient's written consent, and according to the recommendations proposed by Pepys $\&$ Hutchcroft for chemical agents (5) and the European Respiratory Society guidelines (6). On the first day of the SIC, the patient was asked to pass $150 \mathrm{cc}$ of the surfactant from one glass to another for ten minutes. Following this exposure, the $\mathrm{FEV}_{1}$ was monitored every ten minutes for the first hour, and every hour thereafter for the following 12 hours. On another day, the patient was exposed to the agent for 30 minutes under the same conditions of manipulation and $\mathrm{FEV}_{1}$ recording. A SIC with a placebo (olive oil solution) was carried out one day before testing with the suspected agent. Following 30 minutes of exposure to the surfactant, we observed a 25\% decrease in $\mathrm{FEV}_{1} 20$ minutes after exposure had ended, and a $23 \%$ decrease ten hours later (figure 1). This latter decrease was accompanied by symptoms of bronchospasm that required administration of bronchodilator treatment.

The patient was diagnosed with OA caused by the surfactant agent. Once he had permanently left the work setting, he presented a gradual clinical improvement, with normalization of pulmonary function four months after cessation of exposure.

\section{Discussion}

Our case study describes a case of OA produced by a non-ionic surfactant agent used to clean animal carcasses in the meat industry. Surfactants are tensioactive substances that decrease the tension of the contact surface between two phases. The chemical composition of these compounds can vary considerably, although they always contain a hydrophobic part, soluble in apolar substances, and a hydrophilic part, soluble in water or polar substances. Surfactants are classified according to their dissociation power, which is determined by the

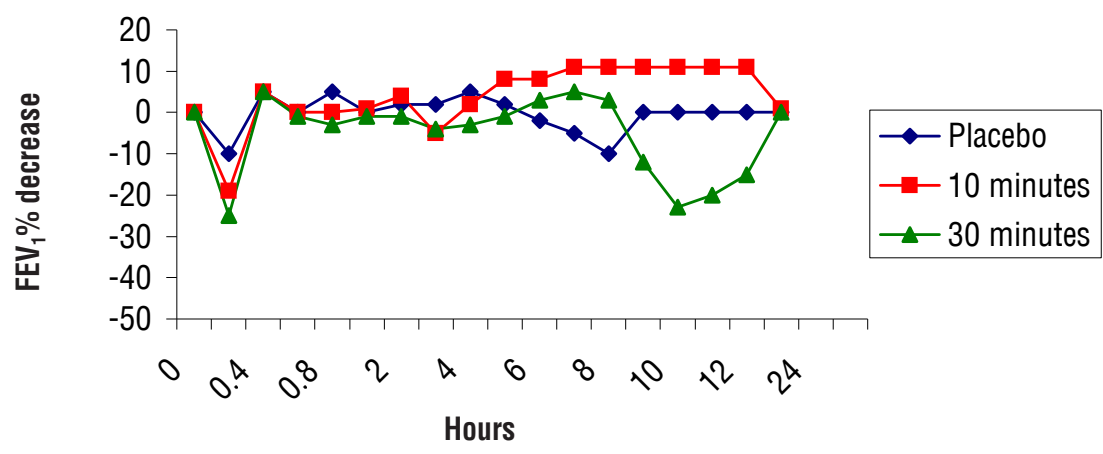

Figure 1. Positive specific inhalation challenge for the surfactant agent. Early forced expiratory volume in one second $\left(\mathrm{FEV}_{1}\right)$ drop of $25 \%$ and later drop of $23 \%$ were observed after an exposure of 30 minutes. Early FEV drop of $19 \%$ and later drop of $11 \%$ were observed after exposure of ten minutes. No positive reaction was observed with the placebo. 
nature of the hydrophilic chain. They can be ionic or non-ionic, the latter being anionic, cationic, or amphoteric, depending on the positive or negative charge of the surface-active part of the molecule. In general, these substances act as detergents with solubilization capacity, and as emulsifiers, humectants, and dispersants.

The patient described in this case report was in direct contact with one of these agents, which impregnated the animal carcasses on which he worked; there were no other substances in his workplace that might explain the symptoms. A positive SIC for the surfactant agent demonstrated the causal relationship.

The mechanism by which surfactants can cause OA has not been defined. The SIC carried out in our patient showed a dual response, consisting of an early $\mathrm{FEV}_{1}$ drop of $25 \%$ and a later drop of $23 \%$, accompanied by respiratory symptoms in the form of sibilant wheezing that required bronchodilator treatment. In the classic interpretation, an early or dual $\mathrm{FEV}_{1}$ decrease following SIC is associated with an IgE-mediated immunological mechanism, whereas other types of response suggest a different mechanism (7). Nevertheless, in our patient there was a dual response, a finding that would indicate an IgE-dependent etiology. Nonetheless, the causative agent is a low molecular weight, non-proteic substance, which (unless it acts as a haptene) should not generate an IgE-mediated immunological response. Although most tensioactive agents have not shown a sensitizing capability, Clausen et al (8) reported that some ionic surfactants (eg, dodecylbenzene sulfonate and dodecyl sulfate) and non-ionic surfactants (eg, dodecyl alcohol ethoxylate) have had an adjuvant effect on specific IgE antibody production in mice. Moreover, we cannot rule out the possibility that an irritative mechanism could also be present in the same manner as has been described for other surfactant agents in the detergent industry $(4,9)$.

To date, only one tensioactive agent, [ie, sodium iso-nonanoyl oxybenzene sulphonate (SINOS)], has been implicated in the genesis of OA (10-11). After the first description of a case of OA secondary to SINOS inhalation occurring in a laboratory technician (10), Stenton et al (11), found a late response following the SIC and a linear relationship between the exposure level and $\mathrm{FEV}_{1}$ decrease, as well as higher positivity in the methacholine challenge in three workers exposed to this agent. In healthy individuals and asthma patients who had no prior contact with SINOS, no changes were seen during the SIC. Based on these results, the authors suggested that the surfactant causes asthma through a specific hypersensitivity mechanism unrelated to its surface-active properties.

The patient described in this case report was exposed to a surfactant composed of alkylamine ethoxylate, and a mixture of alkyleneoxy and ethylenediamine. We cannot exclude that the origin of $\mathrm{OA}$ in this patient could be related to exposure to the amines present in the tensioactive agent. Several studies have related these substances to the development of OA (12). Amines are mainly used in rubber, cosmetics, photography, paints, and detergents, and exposure can also occur in various welding processes (12). More than 40 types of amines have been described as potential causative agents of OA (13), and ethylenediamine is the one most often implicated in the origin of this condition. Dernehl et al (14) provided the first description of OA due to ethylenediamine in persons working in the epoxy resin industry. Using a SIC, Gelfand et al (15) implicated this agent in the occurrence of OA in persons employed in manufacture of shellac. The mechanism by which ethylenediamine causes asthma is not well-defined (12). Recent studies have attributed it to an immunological mechanism, in which the amine acts as a haptene with sensitizing potential, able to provoke an immunological response (16). This hypothesis is sustained by a dual or late response following a SIC, as in the case reported, although considerable variation in the response to skin tests has been described (17-18).

In conclusion, this study describes the case of a patient who developed OA secondary to exposure to a surfactant agent comprised of alkylamine ethoxylate and a mixture of alkyleneoxy and ethylenediamine. Because of the extensive use of these agents in the textile industry, agriculture, metallurgy, and cleaning, it is reasonable to think that their possible relationship with OA could have relevant health implications.

\section{References}

1. Kogevinas M, Anto JM, Sunyer J, Tobias A, Kromhout H, Burney P. Occupational asthma in Europe and other industrialised areas: a population-based study. Lancet. 1999;353:1750-4.

2. Medina Ramon M, Zock JP, Kogevinas M, Sunyer J, Basagaña X, Schwartz J, et al. Short-term respiratory effects of cleaning exposures in female domestic cleaners. Eur Respir J. 2006;27:1196-203.

3. Zock J-P, Kongevinas M, Sunyer J, Almar E, Muniozguren $\mathrm{N}$, Payo F, et al. Asthma risk, cleaning activities, and use of specific cleaning products among Spanish indoor cleaners. Scand J Work Environ Heath. 2001;27(1):76-81.

4. Brant A, Hole A, Cannon J, Helm J, Swales C, Welch J, et al. Occupational asthma caused by cellulase and lipase in the detergent industry. Occup Environ Med. 2004 ;61:793-5.

5. Pepys J, Hutchcroft BJ. Bronchial provocation test in aetiology diagnosis and analysis of asthma. Am Rev Respir Dis. 1975;112:829-59.

6. Gutkowski P. Guidelines on standardized challenge testing for airway hyperresponsiveness. Eur Respir J. 1993;6:1415-6. 
7. Chang-Yeung M, Malo JL. Aetiological agents in occupational asthma. Eur Respir J. 1994;7:346-71.

8. Clausen SK, Sobhani S, Poulsen OM, Poulsen lk, Nielsen GD. Study of adjuvant effect of model surfactants from the groups of alkyl sulfates, alkylbenzene sulfonates, alcohol ethoxylates and soaps. Food Chem Toxicol. 2000;38:1065-74.

9. Sarlo K. Control of occupational asthma and allergy in the detergent industry. Ann Allergy Asthma Immunol. 2003;90(5 suppl 2):32-4.

10. Hendrick DJ, Connolly MJ, Stenon SC, Bird AG, Winterton IS, Walters EH. Occupational asthma due to sodium iso-nonanoyl oxybenzene sulphonate, a newly developed detergent ingredient. Thorax. 1998;43:501-2.

11. Stenton SC, Dennis JH, Walters EH, Hendrick DJ. Asthmagenic properties of a newly developed detergent ingredient: sodium iso-nonanoyl oxybenzene sulphonate. $\mathrm{Br}$ Ind Med. 1990;47:405-10.

12. Bernstein IL, Chan-Yeung M, Malo JL, Bernstein DI, editors. Asthma in the workplace. 3rd ed. New York (NY): Marcel Dekker Inc; 2006. p 555-79.
13. Hagmar L, Nielsen J, Skerfving S. Clinical features and epidemiology of occupational obstructive respiratory disease caused by small molecular weight organic chemicals. Epidemiol Allergic Diseases Monogr Allergy. 1987;21:42-58.

14. Dernehl CU. Hazards to health associated with the use of epoxy resins. J Occup Med. 1963;5:17-21.

15. Gelfand HH. Respiratory allergy due to chemical compounds encountered in the rubber, lacquer, shellac, and beauty culture industries. J Allergy. 1963;34:374-81.

16. Casas X, Badorrey I, Monsó E, Morera J. Asma ocupacional por aminas [Occupational asthma due to amines]. Arch Bronconeumol. 2002;38:93-4.

17. Lam S, Chang-Yeung M. Ethylenediamine-induced asthma. Am Rev Respir Dis. 1980;121:151-5.

18. Nakazawa T, Matsui S. Ethylenediamine-induced late asthmatic responses. J Asthma. 1990;27:207-12.

Received for publication: 30 July 2009 